Case Report

\title{
Clopidogrel-Induced Severe Hepatitis: A Case Report and Literature Review
}

\author{
Hesam Keshmiri, Anuj Behal, Shawn Shroff, and Charles Berkelhammer \\ Department of Medicine, Advocate Christ Medical Center, University of Illinois, Oak Lawn, IL 60453, USA
}

Correspondence should be addressed to Charles Berkelhammer; charlesberkel@aol.com

Received 19 February 2016; Revised 3 May 2016; Accepted 31 May 2016

Academic Editor: Fumio Imazeki

Copyright (C) 2016 Hesam Keshmiri et al. This is an open access article distributed under the Creative Commons Attribution License, which permits unrestricted use, distribution, and reproduction in any medium, provided the original work is properly cited.

Clopidogrel is a commonly prescribed antiplatelet agent that carries a rare risk of hepatotoxicity. We describe a case of severe clopidogrel-induced hepatitis with liver biopsy assessment. Prompt recognition and withdrawal of the offending agent are imperative to prevent progression and potentially fatal liver injury.

\section{Introduction}

Clopidogrel is a commonly used antiplatelet agent, yet only several cases of hepatotoxicity have been described [1-16]. Liver biopsies were not performed in many of these cases. We report a rare case of severe clopidogrel-induced hepatitis with histological assessment.

\section{Case Description}

A 34-year-old male with a history of coronary artery disease and remote coronary artery stent was placed on aspirin plus clopidogrel. His baseline liver biochemistries were normal. He had been on clopidogrel for 2 months 12 years ago without adverse effects but discontinued the medication on his own at that time due to nonadherence. Four and a half months after restarting clopidogrel, he presented with jaundice and fatigue. He denied fever, rash, arthralgias, or abdominal pain. His only other medications were aspirin and metoprolol, which he had been on for many years with normal liver biochemistries.

The patient was not on a statin. He denied recent alcohol or herbal medications. Physical examination was significant only for icterus. There was no hepatosplenomegaly, clubbing, rash, asterixis, or other stigmata of chronic liver disease.

Initial bilirubin was $5.7 \mathrm{mg} / \mathrm{dL}$ (normal $0.2-1.2 \mathrm{mg} / \mathrm{dL}$ ), ALT 1,393 U/L (normal 7-48 U/L), AST 1,418 U/L (normal 7$48 \mathrm{U} / \mathrm{L}$ ), alkaline phosphatase $130 \mathrm{U} / \mathrm{L}$ (normal 35-115 U/L),
INR 1.5, and partial prothrombin time 37 seconds (normal 15-37 seconds). Extensive serologies were negative to hepatitis $\mathrm{A}$, hepatitis $\mathrm{B}$, hepatitis $\mathrm{C}$ (including hepatitis $\mathrm{C}$ RNA), hepatitis E, IgM to cytomegalovirus and Epstein-Barr virus, anti-nuclear antibody, anti-smooth muscle antibody, anti-mitochondrial antibody, anti-liver kidney microsomal antibody, and ceruloplasmin.

Imaging studies were negative, and bile ducts were not dilated, including by ultrasound, computed tomography, and endoscopic retrograde cholangiopancreatography. No gallstones were present on any imaging modality. Liver biopsy revealed severe acute hepatitis with mixed inflammatory portal tract infiltrates including plasma cells, neutrophils and eosinophils, bile ductular reaction, patchy hepatocyte ballooning degeneration, and extensive periportal hepatocyte dropout, without fibrosis (Figure 1).

The patient was diagnosed with clopidogrel-induced severe hepatitis. Despite discontinuing clopidogrel, AST increased to $2,107 \mathrm{U} / \mathrm{L}$, ALT to $1,567 \mathrm{U} / \mathrm{L}$, and bilirubin to $37 \mathrm{mg} / \mathrm{dL}$ (predominately direct bilirubin). INR had increased to 2.1 despite empiric administration of vitamin $\mathrm{K}$. A brief course of prednisone and ursodiol was initiated, with subsequent normalization of liver biochemistries.

\section{Discussion}

We describe a rare case of severe clopidogrel-induced hepatitis, with histological assessment. Our patient's drug-induced 


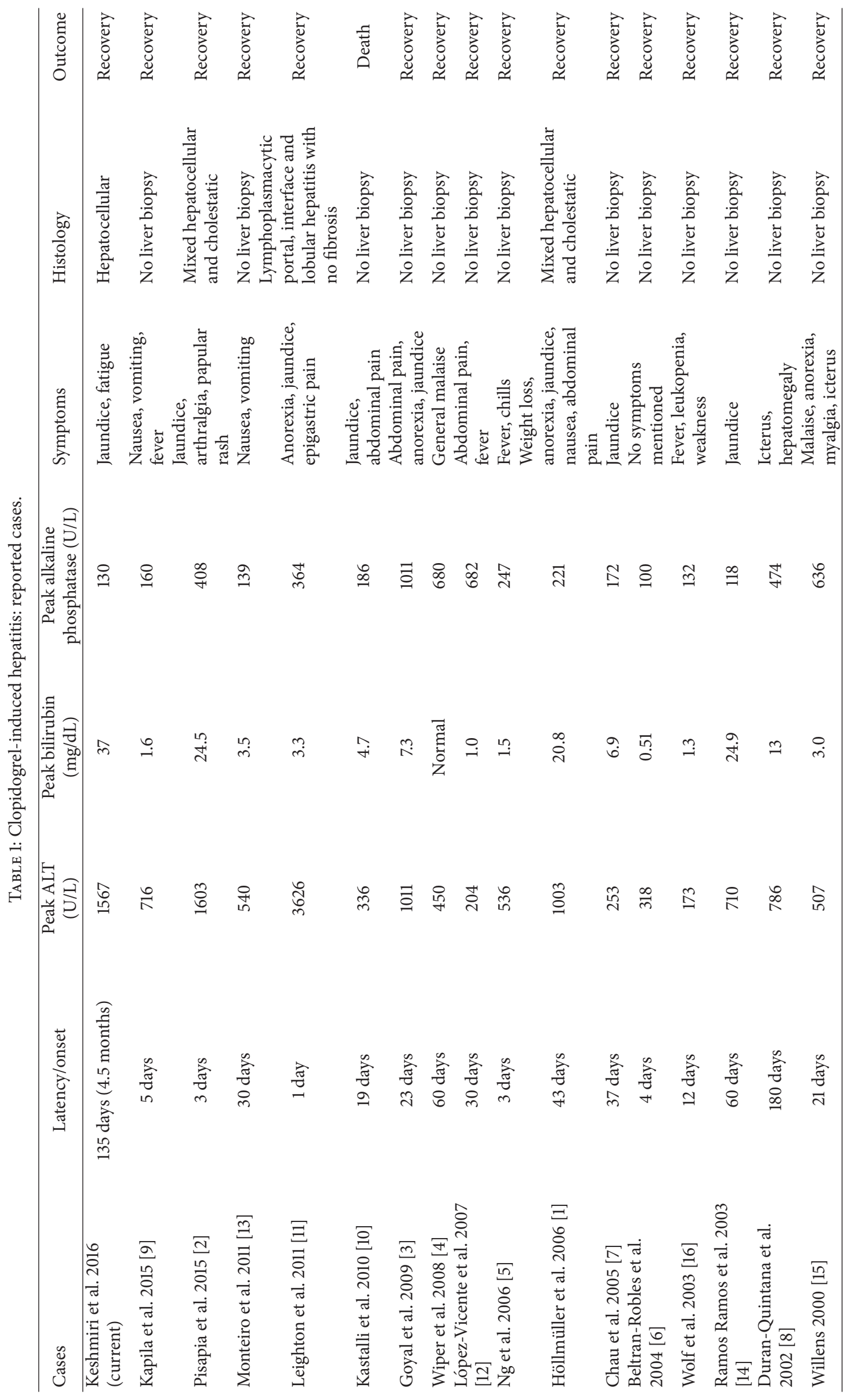




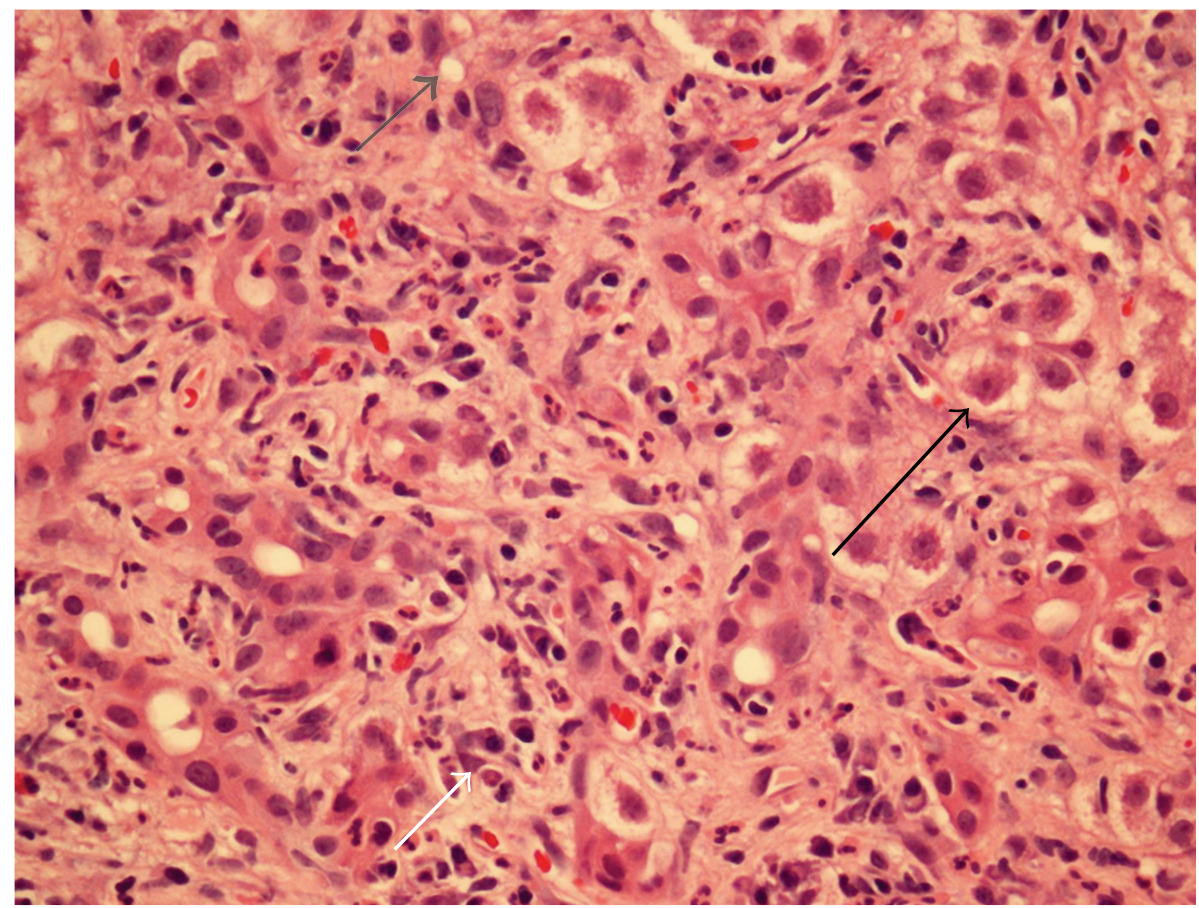

FIGURE 1: Liver biopsy showing severe acute hepatitis with mixed inflammatory portal tract infiltrate (white arrow), patchy hepatocyte ballooning degeneration (black arrow), and extensive periportal hepatocyte dropout (grey arrow).

hepatitis was particularly severe with jaundice (peak bilirubin $37 \mathrm{mg} / \mathrm{dL}$ ), marked elevation of transaminases (peak ALT of $1,567 \mathrm{U} / \mathrm{L}$ ), and coagulopathy (INR 2.1). This degree of hepatic injury portends an increased mortality and underscores the importance of early recognition and discontinuation of the offending agent.

Clopidogrel-induced hepatitis has been described [1-16]. Table 1 lists reported cases in reverse chronological order. The degree of liver injury has ranged from reversible liver injury and recovery $[1-9,11-16]$ to acute hepatic failure and death [10]. Onset of liver injury in these cases ranges between 3 and 180 days [1-16]. Rechallenge confirmed clopidogrelinduced hepatitis in some of these cases [2-5]. Our patient's Naranjo scale and RUCAM (Roussel Uclaf Causality Assessment Method) scores were both 8 , indicating probable druginduced hepatitis $[17,18]$.

Our patients liver biopsy revealed severe hepatocellular injury. This adds to the histological findings in clopidogrelinduced hepatitis, as liver biopsy was only performed in 3 of the previously reported cases $[1,2,11]$. Clopidogrel-induced liver injury can be cholestatic, hepatocellular [11], or mixed hepatocellular plus cholestatic $[1,2]$.

The exact mechanism of clopidogrel-induced hepatitis is unclear. The delayed onset of 4.5 months in our case suggests a toxic-metabolic etiology, whereas the inflammatory infiltrate and response to corticosteroids raise the possibility of a superimposed immune mediated mechanism of injury. Clopidogrel is a prodrug which is metabolized to inactive clopidogrel carboxylate (90\%) and an active metabolite containing a mercapto group (10\%) by cytochrome P450 3A4 and $2 \mathrm{C} 19$. In vitro studies suggest that the active metabolite is responsible for the hepatotoxicity and that high cytochrome 3A4 activities coupled with cellular glutathione depletion are potential risk factors [19]. Interestingly, an earlier antiplatelet agent, ticlopidine, has also been reported to cause druginduced cholestatic hepatitis [20,21].

Clopidogrel-induced hepatitis is a rare but potentially serious adverse effect. A high degree of clinical suspicion is required in patients presenting with abnormal liver biochemistries within a few months after starting clopidogrel. Prompt recognition and discontinuation of the offending agent are necessary, as progressive liver injury and even death can occur.

\section{Competing Interests}

The authors declare that they have no competing interests.

\section{References}

[1] I. Höllmüller, S. Stadlmann, I. Graziadei, and W. Vogel, "Clinico-histopathological characteristics of clopidogrelinduced hepatic injury: case report and review of literature," European Journal of Gastroenterology and Hepatology, vol. 18, no. 8, pp. 931-934, 2006.

[2] R. Pisapia, A. Abdeddaim, A. Mariano et al., "Acute hepatitis associated with clopidogrel: a case report and review of the literature," American Journal of Therapeutics, vol. 22, no. 1, pp. e8-e13, 2015.

[3] R. K. Goyal, D. Srivastava, and K.-D. Lessnau, "Clopidogrelinduced hepatocellular injury and cholestatic jaundice in an elderly patient: case report and review of the literature," Pharmacotherapy, vol. 29, no. 5, pp. 608-612, 2009. 
[4] A. Wiper, M. Schmitt, and D. Roberts, "Clopidogrel-induced hepatotoxicity," Journal of Postgraduate Medicine, vol. 54, no. 2, p. 152, 2008.

[5] J. A. Ng, N. Goldberg, and M. J. Tafreshi, "Clopidogrel-induced hepatotoxicity and fever," Pharmacotherapy, vol. 26, no. 7, pp. 1023-1026, 2006.

[6] M. Beltran-Robles, E. Marquez Saavedra, D. Sanchez-Muñoz, and M. Romero-Gomez, "Hepatotoxicity induced by clopidogrel," Journal of Hepatology, vol. 40, no. 3, pp. 560-562, 2004.

[7] T. N. Chau, K. F. Yim, N. S. Mok et al., "Clopidogrel-induced hepatotoxicity after percutaneous coronary stenting," Hong Kong Medical Journal, vol. 11, no. 5, pp. 414-416, 2005.

[8] J. A. Duran-Quintana, M. Jimenez-Saenz, A. R. Montero et al., "Clopidogrel probably induced hepatic toxicity," Medicina Clínica, vol. 119, article 37, 2002 (Spanish).

[9] A. Kapila, L. Chhabra, A. D. Locke et al., "An indiosyncratic reaction to clopidogrel," The Permanente Journal, vol. 19, no. 1, pp. 74-76, 2015.

[10] S. Kastalli, S. El Aïdli, A. Zaïem, H. Ben Abdallah, and R. Daghfous, "Fatal liver injury associated with clopidogrel," Fundamental \& Clinical Pharmacology, vol. 24, no. 4, pp. 433435, 2010.

[11] S. P. Leighton, C. Gordon, and A. Shand, "Clopidogrel, Turkey and a red herring?” BMJ Case Reports, 2011.

[12] J. López-Vicente, C. Garfia, F. López-Medrano, and C. Yela, "Hepatic toxicity and clopidogrel-induced systemic inflammatory response syndrome," Revista Espanola de Cardiologia, vol. 60, no. 3, pp. 323-324, 2007.

[13] P. H. Monteiro, L. Dos Santos Pinheiro, L. Alvoeiro, M. Lucas, and R. M. Victorino, "Clopidogrel-induced liver failure," JRSM Short Reports, vol. 2, no. 5, p. 40, 2011.

[14] J. C. Ramos Ramos, J. Sanz Moreno, L. Calvo Carrasco, and J. de Dios García Díaz, "Clopidogrel-induced hepatotoxicity," Medicina Clinica, vol. 120, no. 4, pp. 156-157, 2003 (Spanish).

[15] H. J. Willens, "Clopidogrel-induced mixed hepatocellular and cholestatic liver injury," American Journal of Therapeutics, vol. 7, no. 5, pp. 317-318, 2000.

[16] I. Wolf, M. Mouallem, S. Rath, and Z. Farfel, "Clopidogrelinduced systemic inflammatory response syndrome," Mayo Clinic Proceedings, vol. 78, no. 5, pp. 618-620, 2003.

[17] C. A. Naranjo, U. Busto, E. M. Sellers et al., "A method for estimating the probability of adverse drug reactions," Clinical Pharmacology \& Therapeutics, vol. 30, no. 2, pp. 239-245, 1981.

[18] G. Danan and C. Benichou, "Causality assessment of adverse reactions to drugs-I. A novel method based on the conclusions of international consensus meetings: application to druginduced liver injuries," Journal of Clinical Epidemiology, vol. 46, no. 11, pp. 1323-1330, 1993.

[19] A. Zahno, J. Bouitbir, S. Maseneni, P. W. Lindinger, K. Brecht, and S. Krähenbühl, "Hepatocellular toxicity of clopidogrel: mechanisms and risk factors," Free Radical Biology and Medicine, vol. 65, pp. 208-216, 2013.

[20] Y. D. Skurnik, A. Tcherniak, K. Edlan, Z. Sthoeger, M. D. Martínez, and M. Larouche, "Ticlopidine-induced cholestatic hepatitis," Annals of Pharmacotherapy, vol. 37, no. 3, pp. 371-375, 2003.

[21] E. Mambelli, E. Mancini, S. Casanova, A. Di Felice, and A. Santoro, "Severe ticlopidine-induced cholestatic syndrome," Blood Purification, vol. 25, no. 5-6, pp. 441-445, 2008. 


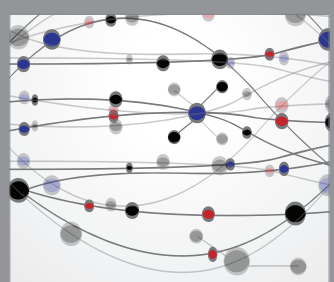

The Scientific World Journal
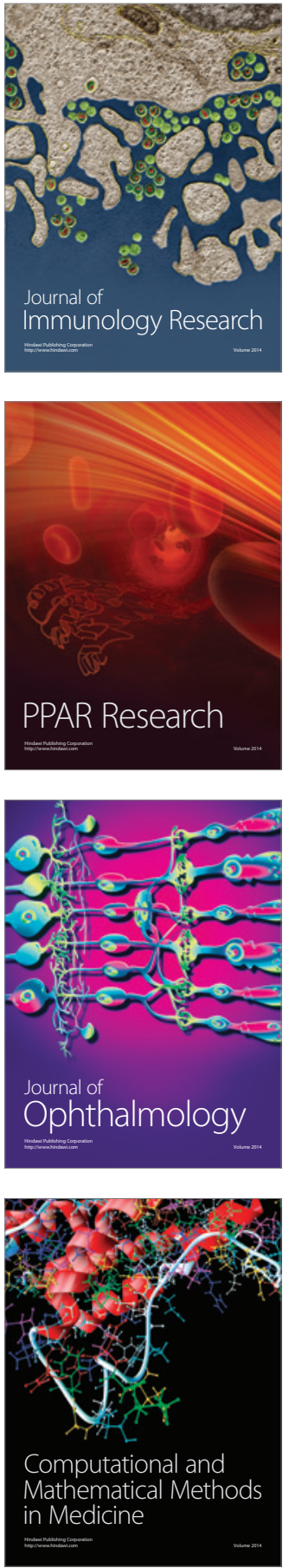

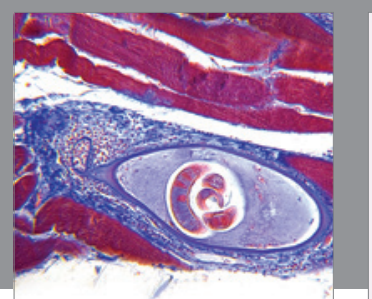

Gastroenterology Research and Practice

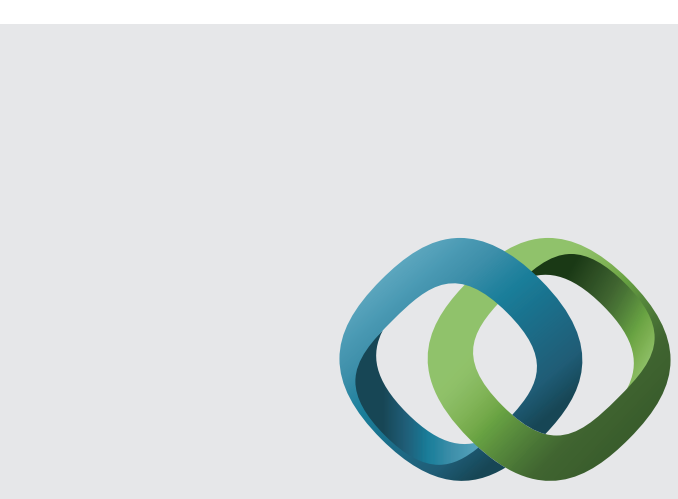

\section{Hindawi}

Submit your manuscripts at

http://www.hindawi.com
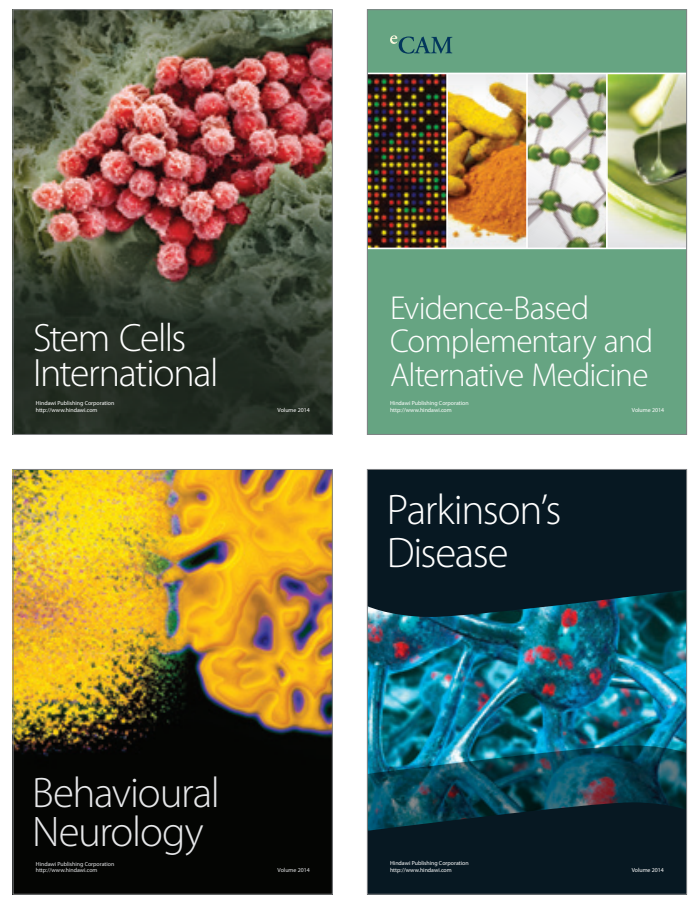
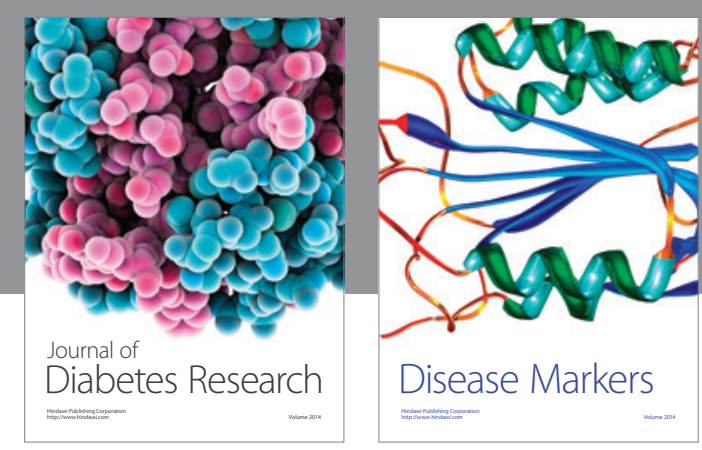

Disease Markers
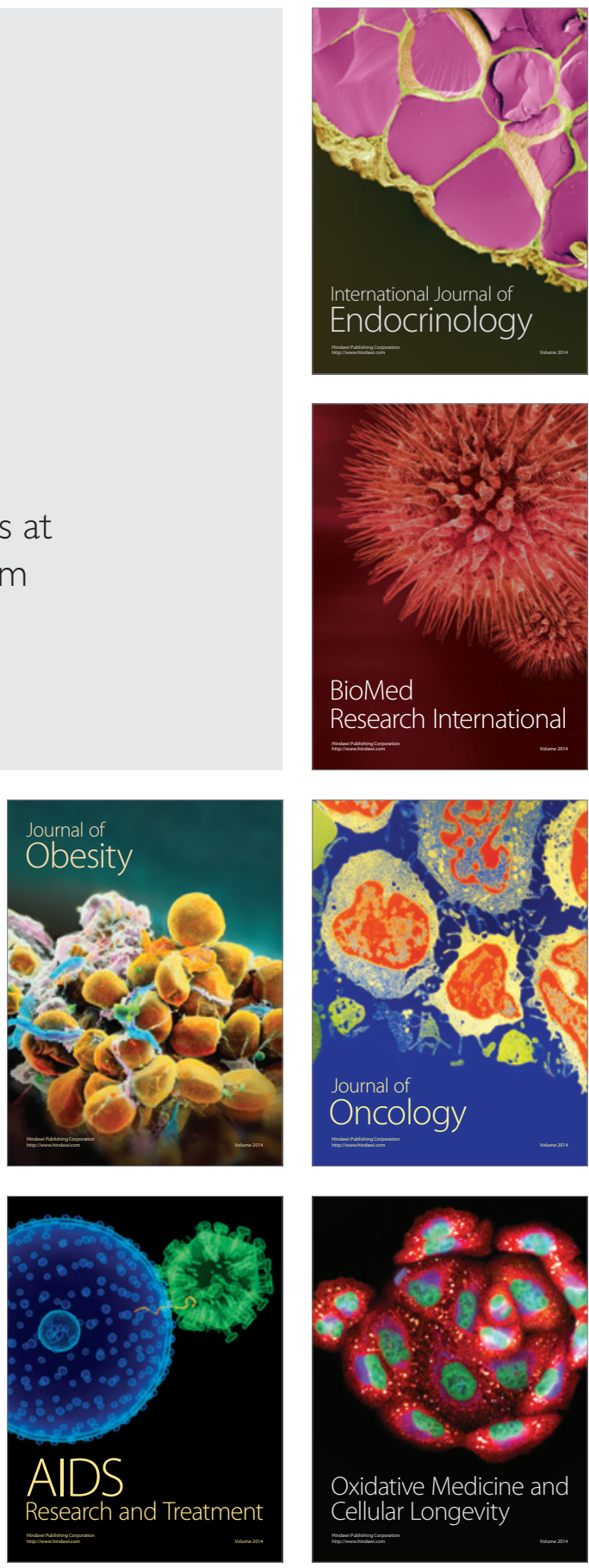